\title{
Simulated networks with realistic neuronal morphologies show small-world connectivity
}

\author{
Alexander de Ridder, Frank Postma, Sacha Hoedemaker, Randal Koene, \\ Jaap van Pelt and Arjen van Ooyen*
}

Address: Department of Integrative Neurophysiology, Center for Neurogenomics and Cognitive Research, VU University Amsterdam, De Boelelaan 1085, 1081 HV Amsterdam, the Netherlands

Email: Arjen van Ooyen* - arjen.van.ooyen@cncr.vu.nl

* Corresponding author

from Eighteenth Annual Computational Neuroscience Meeting: CNS*2009

Berlin, Germany. 18-23 July 2009

Published: 13 July 2009

BMC Neuroscience 2009, I0(Suppl I):P5 doi:I0.1 I86/I47I-2202-I0-SI-P5

This abstract is available from: http://www.biomedcentral.com/I47/-2202/I0/SI/P5

(c) 2009 de Ridder et al; licensee BioMed Central Ltd.

Activity dynamics underlying cognition depends crucially on the patterns and strengths of synaptic connections between neurons. Synaptic connections can form when axonal and dendritic branches of neurons come sufficiently close to each other [1]. The geometry of neuronal arborization is therefore an important determinant of synaptic connectivity. How neuronal morphology shapes neuronal network connectivity is, however, still poorly understood.

To address this question, we used our modelling tool NETMORPH, a simulation framework for generating realistic neuron morphologies based on rules for neuronal development (Figure 1). The model neurons grow out independently of each other. Synapses are formed during outgrowth when axons and dendrites come sufficiently close to each other (within a distance of $2 \mu$ [2]). The synaptic locations are thus purely based on the 3D cell geometries. The network consisted of 250 model neurons optimised for the geometry of rat layer $2 / 3$ pyramidal neurons. The neurons were randomly placed in a sphere with a $93 \mu$ radius and a minimum neuron separation of $20 \mu$. Connectivity properties were analysed using a battery of measures, including small-worldness of the network. This property is defined as $\gamma / \lambda$, with $\gamma=C_{\text {original }} / C_{\text {random }}$ and $\lambda=$ $L_{\text {original }} / L_{\text {random' }}$ where $C$ is the clustering coefficient and $L$ is the total mean path length. The ratio $\gamma / \lambda$ is typically greater than one for small-world networks [3].

Interestingly, in all networks analysed, $\gamma / \lambda$ values appear in the range [1.1-1.5], indicating small-world connectiv-

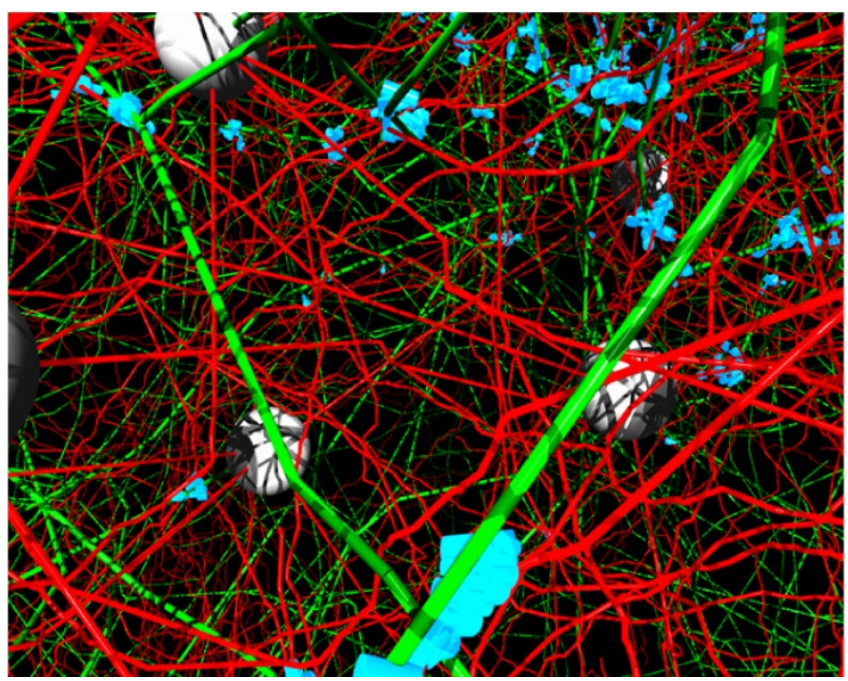

Figure I

Example of a NETMORPH simulated network. Green: axons; red: dendrites; white: somata; blue: synapses. 


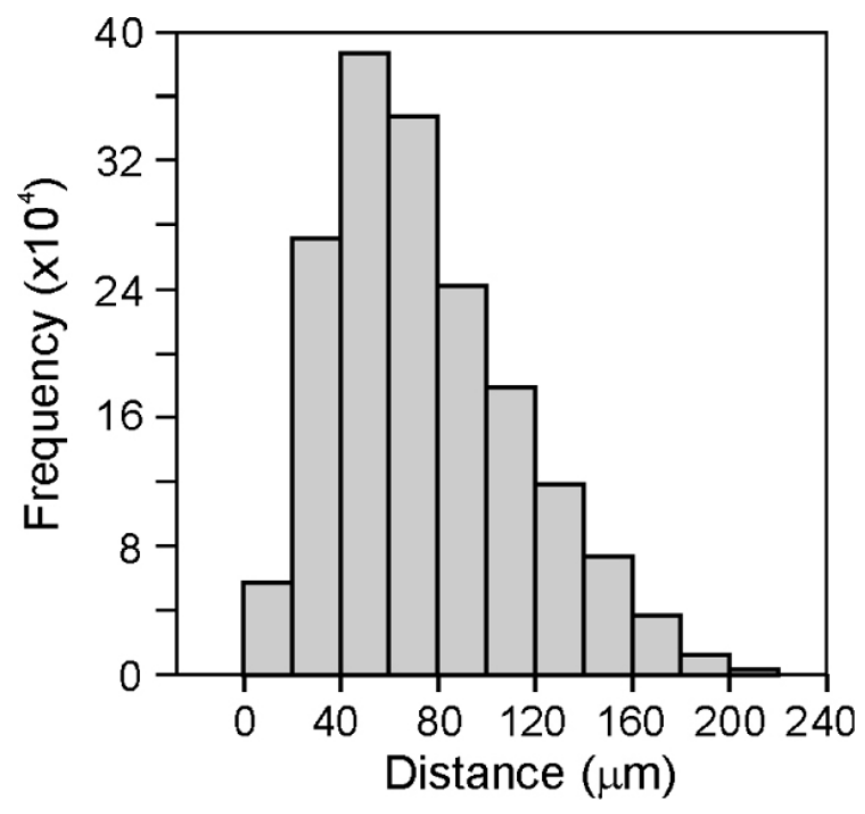

Figure 2

Distribution of Euclidean distances of synapses to postsynaptic somata.

ity. Other connectivity measures, such as Euclidean distances from synaptic locations to postsynaptic somata (Fig. 2) show distributions that are similar to experimentally observed ones [4].

Our preliminary findings indicate that realistic neuronal morphologies, simple synapse formation rules and independently developing neurons can already create networks with realistic connectivity patterns and small-world properties. Our study provides insight into the impact of neuronal geometry on network connectivity. In future work we will consider different cell types, different neuron densities and increased size of the network.

\section{Acknowledgment}

This work was supported by EU MC-RTN NEURoVERS-it (019247), and BIO-ICT Project SECO (216593).

\section{References}

I. Peters A: Thalamic input to the cerebral cortex. Trends Neurosci 1979, 2: I I83-I I85.

2. Stepanyants A, Chklovskii DB: Neurogeometry and potential synaptic connectivity. Trends Neurosci 2005, 28:387-394.

3. Humphries MD, Gurney K, Prescott TJ: The brainstem reticular formation is a small-world, not scale-free, network. Proc Biol Sci 2006, 273:503-5II.

4. Feldmeyer D, Lübke J, Silver RA, Sakmann B: Synaptic connections between layer 4 spiny neurone-layer $2 / 3$ pyramidal cell pairs in juvenile rat barrel cortex: physiology and anatomy of interlaminar signalling within a cortical column. J Physiol 2002, 538:803-822.
Publish with Biomed Central and every scientist can read your work free of charge

"BioMed Central will be the most significant development for disseminating the results of biomedical research in our lifetime. " Sir Paul Nurse, Cancer Research UK

Your research papers will be:

- available free of charge to the entire biomedical community

- peer reviewed and published immediately upon acceptance

- cited in PubMed and archived on PubMed Central

- yours - you keep the copyright

Submit your manuscript here:

http://www.biomedcentral.com/info/publishing_adv.asp 